\title{
Computational water stress indices obtained from thermal image analysis of grapevine canopies.
}

Sigfredo Fuentes ${ }^{* 1}$, Roberta De Bei ${ }^{1}$, Joanne Pech ${ }^{2}$ and Stephen Tyerman ${ }^{1}$

${ }^{1}$ The University of Adelaide, School of Agriculture, Food and Wine, Plant Research Centre PMB 1 Glen Osmond, 5064, SA, Australia.

${ }^{2}$ South Australia Research and Development Institute (SARDI). GPO Box 397, Adelaide SA 5001, Australia.

*Corresponding author: sigfredo.fuentes@adelaide.edu.au

\section{ABSTRACT}

Thermal imaging of crop canopies has been proposed more than a decade ago as a sensitive methodology to determine water status of different crops. This paper describes the development of a semi-automated and automated methodology using MATLAB® programming techniques to analyse infrared thermal images taking into consideration the pitfalls pointed out previously in the literature. The proposed method was tested in an irrigation reduction and recovery trial for Chardonnay in the 2010-11 season and in the 2009-10 season from seven varieties in field conditions. There was a clear separation (assessed by principal component analysis) between control and recovery compared to stress treatments using leaf area index (LAI), stomatal conductance, stem water potential and indices derived from canopy temperatures measured by infrared imaging. High and significant correlations were found between canopy temperature indices and other measures of water stress obtained in the same vines that were independent of $L A I$. Furthermore, a fully automated analysis method has been proposed using ancillary weather 
information obtained from the same locations of infrared thermal images. This paper is a first step towards automation of infrared thermography acquisition and analysis in the field for grapevines and other crops.

Key words: infrared thermography, remote sensing, MATLAB® programming, crop water stress index, irrigation scheduling.

\section{INTRODUCTION}

Canopy conductance $\left(g_{c}\right)$, taken as the averaged leaf conductance $\left(g_{L}\right)$ for the whole canopy, is one of the most sensitive parameters to water stress. This parameter can be estimated from leaf-based measurements of stomatal conductance $\left(g_{s}\right)$, after scaling to the whole canopy using leaf area index $(L A)$ to obtain $g_{c}$. However, this method of estimating canopy conductance has disadvantages that limit its practical use for irrigation scheduling (Lu et al., 2003). These include: i) spatial variability of $g_{s}$ within the leaf, canopy, irrigation block or the whole vineyard (Jones and Vaughan, 2010); ii) time consuming, depending on the number of measurements per leaf and leaves per canopy; iii) instrumentation required can be cost prohibitive.

Canopy conductance can also be estimated from infrared thermal imaging providing "snapshots" of the whole canopy, or several rows of grapevines when taken from a height above the canopy, making this method a more integrative approach (Moller et al., 2007; Wang et al., 2010). Furthermore, besides still thermal images, currently there are cameras available that can record infrared videos, allowing the incorporation of an in-built geographic 
positioning system (GPS) that can be used to produce spatial maps with canopy temperature distributions and potentially distribution of crop water stress indices (CWSI) within a field (i.e. SC series cameras, FLIR Systems, Portland, USA).

Canopy temperature has been proposed as an indicator of plant water stress since the 1960s (Tanner, 1963) based on the cooling effect of the transpiration process. Since then, technological advances have allowed improved applications in agriculture from temperature sensors clamped on leaves to short range remote sensing, such as infrared thermometry and thermal imaging. The latter, has been recognised as a more suitable method to assess variability of thermal properties within grapevine canopies (Cifre et al., 2005; Jones, 2004; Jones et al., 2002b). Since thermal images are effectively snapshots, they can include non-leaf material within the image of canopies, such as branches, wires from training systems, bunches, sky and soil (Figure 1a), which need to be excluded from the analysis (Fuentes et al., 2005a; Jones, 1999a; Jones, 1999b; Jones et al., 2002b). Non-leaf material can be excluded from thermal images using a variety of methods, such as: i) manual selection of leaf material using polygonal or user defined shapes, ii) the use of "wet" and "dry" reference materials (or leaves) "painted" with petroleum jelly and water within the thermal image (Figure 1b) in order to obtain the maximum $\left(T_{\text {dry }}\right)$ and minimum $\left(T_{\text {wet }}\right)$ canopy temperatures, respectively to exclude non-leaf material outside this range (Fuentes et al., 2005a; Guilioni et al., 2008; Jones, 1999b; Jones et al., 2002b; Lindenthal et al., 2005), iii) other studies have proposed estimating $T_{d r y}$ and $T_{\text {wet }}$ using 
ancillary weather variables to derive these parameters using energy balance algorithms (Moller et al., 2007).

A wide range of research has been done recently in grapevines to obtain CWSI based on thermal image analysis, which correlate to other well established plant water stress parameters, such as $g_{s}$ and leaf or stem water potential $\left(\Psi_{s}\right)$ (Ferrini et al., 1995; Grant et al., 2007a; Guilioni et al., 2008; Jones, 1999a; Jones, 1999b; Jones et al., 2002b; Moller et al., 2007; Stoll et al., 2008c). Furthermore, the use of thermal images has been proposed for pathogen detection, which can also affect thermal and water transference dynamics of leaves or sections of the canopy with the atmosphere (Lindenthal et al., 2005; Stoll et al., 2008a; Stoll et al., 2008b; Stoll et al., 2008c).

Though the potential of infrared imaging for irrigation scheduling has been highlighted (Jones, 2004) there are some disadvantages and specific considerations that need to be taken into account, such as: i) windy conditions that can complicate the accuracy of the grapevine water status assessment due to rapid changes in $g_{s}$ within a single canopy (Guilioni et al., 2008); ii) inclusion of non-leaf material in the analysis; iii) difficulty in the analysis of large volumes of data, since every pixel from each image is effectively a temperature reading (usually 5 megapixels per image) (Wang et al., 2010); iv) grapevines offer an extra complication due to the heterogeneity of their canopies compared to broad acre crops with more homogeneous canopies and closed canopies or cover (Grant et al., 2007a; Jones, 1999b; Jones et al., 2002b). To minimise thermal variability within grapevine canopies, it has been proposed the shaded side rather than the sunny side be used to obtain thermal images (Jones et al., 2002b); and finally, v) Guilioni et al. (2008) 
identified a problem of consistency in previous studies related to the way that reference leaves were treated with both petroleum jelly and water to obtain $T_{\text {dry }}$ and $T_{\text {wet, }}$ respectively. Some studies obtained reference leaves by painting only one side while others were applying on both sides of the reference leaves.

Initial analyses of infrared thermal images were achieved using specialised computer programs from the IR camera providers, such as FLIR QuickReport $\circledast$ and Reporter Pro® (FLIR Systems, Portland, USA) (Cohen et al., 2005). These software packages offer basic computations of mean, maximum and minimum temperature from regions of interest (ROI) obtained by drawing ROls by hand using either square, polygonal or user-defined shape selections. This technique is time consuming considering that a considerable number of thermal images are required to have a representative assessment of the spatial variability of plant water status of an irrigation block or a complete vineyard.

A combined approach using visible and thermal images has been proposed by pre-analysing the visible Red, Blue and Green (RGB) components of each image to separate leaf and non-leaf material by colour discrimination (Leinonen and Jones, 2004a) using a custom made code in C+ (Moller et al., 2007). However, this method requires further steps in the analysis and an extra three-fold data volume to be analysed, considering visible (RGB) and infrared data per canopy. This approach also lacks the option of batch analysis for large quantities of images. An automated method has been proposed by Wang et al. (2010), using a similar approach that consists of analysing visible and thermal images through a combination of colour 
identification and Gaussian mixture distribution extraction techniques to obtain CWSI. However, this work only offered comparisons of results (CWSI) with $\psi_{s}$ as a physiological parameter with low and statistically non-significant correlations.

Considering previous research, a simple and robust automated imaging analysis technique is required for a rapid and effective assessment of water status of grapevines. This system would allow the implementation of thermal image analysis to schedule irrigation using a plant-based technique. In this paper, we have focused on the problems identified in previous work to develop an automated methodology for thermal image analysis using the $T_{\text {dry }}$ and $T_{\text {wet }}$ reference leaves and calculated $T_{\text {dry }}$ and $T_{\text {wet }}$ using leaf energy balance models and matrix analysis techniques. Furthermore, this methodology can be applied to analyse thermal images and thermal videos automatically using the versatility offered by MATLAB® programing to manage very large matrices of data as indexed images in an efficient and rapid way. A spatial data analysis technique is also proposed to assess data quality within thermal images and to identify potential sources of temperature variability within canopies, which can be associated with windy conditions, thermal influence of bare soils (in the case of low canopies), pathogen or insect attacks, or any other biotic and abiotic factors affecting the $g_{L}$ and therefore the index obtained from infrared thermal image analysis $\left(I_{G}\right)$, which is proportional to $g_{L}$ (Jones et al., 2002b) and CWS/ within canopies.

\section{MATERIALS AND METHODS}


Thermal images and physiological data were collected during the seasons 2009-10 and 2010-11 in Australia. A detailed study, incorporating leaf area index, was conducted on the variety Chardonnay within an irrigation reduction and recovery trial (Chardonnay trial). The automated system was also tested on infrared thermal images from a fully irrigated variety trial (variety trial). Infrared thermal images and physiological data acquisition was from 12:00 and 14:00 hours (LST), which coincides with the maximum atmospheric demand recorded at the field sites. These data is regarded as "midday" in this paper.

Experimental sites and plant material

\section{Chardonnay trial}

The experiment was carried out during February 2011 in an irrigation reduction and recovery after water restrictions have been applied trial within a commercial Chardonnay vineyard at Qualco (SA), (Yalumba Nurseries). This trial started in the 2008-09 season using a total area of 3.69 ha with a randomised block design considering four blocks (Figure 2). The vines in the trial are 8-years-old grafted on Ramsey rootstock and trained on a two - wire vertical trellis system with row spacing of $1.8 \mathrm{~m}$ between vines and $3 \mathrm{~m}$ between rows. From this trial, three irrigation strategies were considered for this study: full irrigation or control (C), and reductions to, 30\% (30S) and 10\% (10S) of the control. The Control treatment represented the amount of irrigation that is normally applied to the vines in a season (5 ML ha- ${ }^{-1}$ year $\left.^{-1}\right)$. Each treatment consisted of three rows divided into three sections of 30 vines 
each. In the $2009-10$ season one of these three sections for each treatment was changed to the control irrigation level in order to study the physiological changes of vines in recovery from irrigation reduction. Thus, two recovery treatments were added, these were 30\% (30R) and 10\% (10R). All treatments were irrigated with Netafim Dripmaster pressure compensated in-line drippers with a $2.3 \mathrm{~L} \mathrm{~h}^{-1}$ of flow. All irrigation events were scheduled to apply $6 \mathrm{~mm}$ in 4 hr. To apply the reductions in irrigation volume, the interval between irrigations was increased using the Irrigated Crop Management Service (ICMS) Water Budgeting Tool (SARDI). Infrared imaging acquisition and physiological measurements were made in parallel on the same vines at midday for three consecutive days in the trial site at the post-veraison stage $\left(17^{\text {th }}, 18^{\text {th }}\right.$ and $19^{\text {th }}$ of February 2011).

\section{Variety trial}

The variety experiment was carried out in the Coombe vineyard at the Waite Campus of the University of Adelaide, South Australia, during the 2009-10 season. Infrared thermal images were acquired in two consecutive dates, the $19^{\text {th }}$ and $20^{\text {th }}$ of January 2010 . Three red and three white wine varieties were selected for the study. The varieties were: Shiraz, Merlot, Pinot Noir, Chardonnay, Pinot Gris and Sauvignon Blanc. All varieties are own-rooted, planted in 1991 with a vine spacing of $1.8 \mathrm{~m}$ in the row and $3 \mathrm{~m}$ between rows. The training system for all varieties is a bilateral spur pruned cordon with the shoots vertically positioned. All vines were drip irrigated twice per week by in-line drippers discharging $1.5 \mathrm{~L} / \mathrm{h}$. Infrared imaging acquisition and 
physiological measurements were performed in parallel on the same vines at midday for the two days of measurements.

\section{Infrared thermal image acquisition}

Thermal images were acquired from canopies using an infrared camera FLIR T-series (Model B360) (FLIR Systems, Portland USA), with a resolution of 320 $x 240$ pixels. The camera measures temperature in the range of $-20{ }^{\circ} \mathrm{C}$ to $1200{ }^{\circ} \mathrm{C}$. The thermal sensitivity of the camera is $<0.08{ }^{\circ} \mathrm{C} @+30^{\circ} \mathrm{C} / 80 \mathrm{mK}$ with a spatial resolution of 1.36 miliradians. Each pixel is considered an effective temperature reading in degrees Celsius $\left({ }^{\circ} \mathrm{C}\right)$. Infrared images were acquired from the shaded side of the canopy to reduce variability in the estimation of $I_{G}$ and $C W S I$ to be compared with other plant water status indicators, such as $g_{L}$ and $\psi_{s}$ (Fuentes et al., 2005a; Jones et al., 2002b). One thermal image from the canopy, from each of four plants per treatment (Chardonnay trial) and per variety (Variety trial), were obtained from a constant distance of $2.5 \mathrm{~m}$ perpendicular to the row direction (distance between rows is $3 \mathrm{~m})$. Infrared thermography parameters $\left(I_{G}\right.$ and $C W S I$ ) were compared with physiological measurements acquired immediately after obtaining each thermal image from the same vines. All thermal images were acquired on clear days with minimal wind conditions, which were assessed visually by leaf movement at the top of canopies previous thermal image acquisition, to avoid the influence of air movement on temperature variability

within the canopy and reference leaves. Reference temperatures ( $T_{\text {wet }}$ and $\left.T_{d r y}\right)$ were obtained by selecting two non-detached mature and representative leaves from a reference plant per treatment. These leaves were "painted" on 
the abaxial and adaxial sides two minutes before taking the thermal images. One leaf was painted with a solution of water and detergent (dishwashing soap) $0.01 \%(\mathrm{v} / \mathrm{v})$ to obtain the $T_{\text {wet }}$ reference and the second leaf with liquid petroleum jelly (Vaseline) to obtain the $T_{d r y}$ reference.

Algorithms used

Crop water stress index (CWSI) was calculated using the following equation, proposed by Jones (1992) modified from Idso et al. (1981) after determining $T_{\text {dry }}$ and $T_{\text {wet: }}$

CWSI $=\frac{T_{\text {canopy }}-T_{\text {wet }}}{T_{\text {dry }}-T_{\text {wet }}}$

Equation 1

where $T_{\text {canopy }}$ is the actual canopy temperature obtained from the thermal image and $T_{\text {dry }}$ and $T_{\text {wet }}$ are the reference temperatures $\left({ }^{\circ} \mathrm{C}\right)$, obtained using the method of painting both sides of reference leaves with petroleum jelly and water respectively (Idso, 1982; Jones, 1992).

An index, proportional to leaf conductance to water vapour transfer $\left(g_{L}\right)$ can be obtained using the relationship proposed by Jones et al. (2002) as follows:

$I_{G}=\frac{T_{\text {dry }}-T_{\text {canopy }}}{T_{\text {canopy }}-T_{\text {wet }}}=g_{L}\left(r_{\text {aw }}+\left(\frac{s}{y}\right) r_{H R}\right)$ Equation 2

where $r_{a w}=$ boundary layer resistance to water vapour, $r_{R H}=$ the parallel resistance to heat and radiative transfer (Jones, 1992), $V=$ psycrometric constant and $s=$ slope of the curve relating saturation vapour pressure to temperature (Jones, 2004);(Jones et al., 2002b). 
Thermal image analysis

Thermal images were analysed using custom code written in MATLABß 2010b (Mathworks Inc., Natick, MA, USA) and the Image Analysis Toolbox®. The use of the automated code requires that all thermal images (JPEG) are saved into a Microsoft Excel® file, in which each image is stored as a separate worksheet. To change the file formatting, thermal images were loaded firstly using the FLIR QuickReport® (FLIR Systems, Portland USA) software and exported to Excel® (FLIR Systems, Portland, USA). This process can be automated using the FLIR ThermaCAM ${ }^{\mathrm{TM}}$ Researcher software (FLIR Systems, Portland USA).

Thermal images are imported by the code and stored in matrix variables automatically, which can be treated in MATLAB as 8-bit indexed images. Therefore, each variable assigned in MATLAB corresponds to an indexed image represented by a matrix $A_{(m, n)}$ with the pixel position $(m, n)$ as indices and temperature $(T)$ in ${ }^{\circ} \mathrm{C}$ as the values:

$A(m, n)=\left(\begin{array}{ccc}T_{1,1} & \cdots & T_{1, n} \\ \vdots & \ddots & \vdots \\ T_{m, 1} & \cdots & T_{m, n}\end{array}\right)$ Equation 3

Since $(m, n)$ represents pixels in the thermal image, the maximum thermal image dimension is constant and corresponds to $m=320$ and $n=240$ pixels.

Analysis of thermal images from reference leaves to obtain $T_{\text {dry }}$ and $T_{\text {wet }}$ 
As a first step, the code asks which spreadsheets correspond to thermal images containing the reference leaves ( $T_{\text {wet }}$ and $\left.T_{\text {dry }}\right)$. The user inputs are numerical and correspond to the number of the specific spreadsheets from 1 to $\mathrm{n}$. Once the reference images are specified, the data is uploaded to obtain $T_{d r y}$ and $T_{\text {wet }}$ as an average of the region of interest (ROI) delimited by the user on the image. For this purpose, a selector is displayed on the image to obtain $T_{\text {wet }}$ on the cooled leaf and $T_{d r y}$ on the heated leaf. Once these thresholds are calculated as the average $T\left({ }^{\circ} \mathrm{C}\right)$ value of the specific ROI, the code asks for the images to be analysed in batch.

Analysis of thermal images from ancillary information to obtain $T_{\text {dry }}$ and $T_{\text {wet }}$ Ancillary information can be obtained using sensors at the same time and position from which the infrared thermography images are obtained. Micrometeorological data was used from the LiCOR 6400 readings that were made in the same canopies from which infrared thermal images were obtained (see Physiological measurements). Further meteorological data was obtained from a nearby automatic meteorological station (Measurement Engineering Australia, Adelaide). Ancillary meteorological measurements were used to calculate local $T_{d r y}$ and $T_{\text {wet }}$ reference temperatures using the basic leaf balance approach (Jones, 1999a; Jones et al., 2002b). The algorithms used to compute $T_{d r y}$ and $T_{\text {wet }}$ were:

$$
T_{d r y}-T_{a}=\frac{r_{H R} R_{n i}}{\rho c_{p}}
$$


where $T a$ is the air temperature measured at the same positions and time as infrared thermography acquisition, $r_{H R}$ is the parallel resistance to heat and radiative transfer, $R_{n i}$ is the net isothermal radiation (the net radiation that would be received by an equivalent surface at air temperature), $\rho$ is the density of air and $c_{p}$ is the specific heat capacity of air. This formula uses the concept of isothermal radiation and assumes a dry surface with the same aerodynamic and radiative properties, in which the sensible heat loss will equal the net radiation absorbed (Jones, 1992).

$T_{\text {wet }}-T_{a}=\frac{r_{H R} r_{a W} \gamma R_{n i}}{\rho c_{p}\left[\gamma\left(r_{a W}\right)+s r_{H R}\right]}-\frac{r_{H R} \delta e}{\gamma\left(r_{a W}\right)+s r_{H R}}$

were $r_{a w}$ is the boundary layer resistance to water vapour transfer (assumed to be largely determined by the stomatal resistance), $\gamma$ is the psychrometric constant, $s$ is the slope of the curve relating saturation vapour pressure to temperature, $\delta e$ is the water vapour pressure deficit in the air.

\section{Automated sub-division of thermal images}

Based on the hypothesis that wind velocity will affect primarily the upper part of canopies, due to architectural arrangement of rows in a vineyard configuration, the code sub-divides each thermal image to assess wind velocity on spatial variability of canopy temperatures. For this purpose, each image $\left(A_{(m, n)}\right)$ is automatically divided in to three $(d)$ horizontal sections corresponding to the top $\left(A_{t}\right)$, middle $\left(A_{m}\right)$ and bottom $\left(A_{b}\right)$ for differential analysis. 


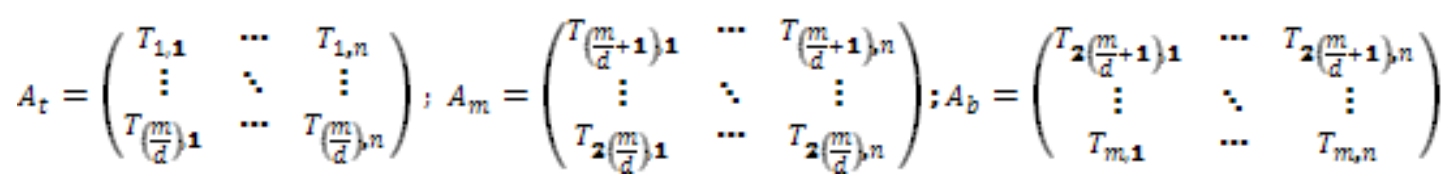

Equations 1 and 2 are used to analyse separately each sub-matrix to obtain $C W S I$ and $I_{G}$ for the top, middle and bottom sections of each canopy.

\section{Customised sub-division}

For a more detailed spatial analysis of canopies, a second tool was developed to divide each image $\left(A_{(m, n)}\right)$ in a number of sub-images defined by the user (d). This algorithm was previously used for $L A /$ estimation using gap analysis and image sub-division (Fuentes et al., 2008). This tool divides each thermal image in $n \times m$ subdivisions, where $n=m$ and corresponds to the user input (i.e. a sub-division input $d=5$, will divide the image in $5 \times 5=25$ subdivisions). For each sub-division the $I_{G}$ index can be calculated (Eq. 2), which allows generating a $2 \mathrm{D}$ image to discriminate sections of the canopy that could be influenced by biotic and abiotic factors that can explain variability within a single canopy. This analysis can be visual or statistical based on the analysis of variability of means for $I_{G}$ values.

To test the customised sub-division tool, a $30 \mathrm{~cm}$ (diameter) fan was located facing the top of canopies from a distance of $2 \mathrm{~m}$ of well-irrigated vines (control) in the Chardonnay trial. The windspeed was measured using a portable watch with wind sensor (WindMaster® Swiss - made Sensor, Swiss). The windspeed $(u)$ was maintained approximately constant at $1.39 \mathrm{~m} \mathrm{~s}^{-1}$. Infrared images were obtained after 2 minutes of applying wind. From these thermal images the $I_{G}$ index was calculated using the sub-division (top, middle 
and bottom) to obtain any statistical differences in these three sections of the canopy. For the customised sub-division tool, a $d$ value of $d=12$ was used, giving a total number of sub-divisions of 144 .

\section{Automated filtering of non-leaf material from sub-images}

For each thermal image, a simple filter rule was used to exclude all $T$ values above $T_{d r y}$ and below $T_{\text {wet, }}$ which were considered non-leaf material or sun exposed leaf material as follows:

$$
A_{i f}=T_{\text {wat }} \geq A_{(t, m, b)} \geq T_{\text {dry }} ; \mathbb{R}\left(A \rrbracket_{(t, m, b)} \neq A_{\text {if }}\right) \notin A_{i f}
$$

where $A_{\text {if }}$ is a sub-image filtered matrix with values of $T$ that meet the rule set in Eq. 4 and " 0 " values replacing $T$ that does not meet the filter rule (Figure 3b). After filtering, calculations of mean temperatures, standard deviation of the mean, $I_{G}$ and $C W S I$ can be obtained for each sub-matrix.

\section{Outputs handling}

Numerical outputs from thermal images analysis are automatically saved in an Excel® file containing relevant data, such as $T_{\text {dry }}, T_{\text {wet, }}$ mean canopy temperature $\left(T_{c}\right)$, maximum canopy temperature $\left(T_{\max }\right)$, minimum canopy temperature $\left(T_{\min }\right)$, standard deviation of temperatures in the canopy $\left(S D_{T}\right), I_{G}$ and CWSI for the entire thermal image, for the three main sub-divisions or for the customised sub-division methods. The program has also an option to obtain frequency distribution of temperatures for determined thermal images (Figures 1c and 1d). 


\section{Physiological measurements}

Stem water potential $\left(\Psi_{s}\right)$

Measurements of $\psi_{s}$ were performed on each plant studied using a Scholander type pressure chamber (PMS Instruments, Model 1005, Albany, OR. USA). For this purpose, a fully expanded mature leaf was selected from each plant and bagged for at least 30 minutes before each measurement with a plastic bag coated with aluminium foil $(n=24)$. No more than $30 \mathrm{sec}$ elapsed between the leaf cutting and measurement of bagged leaves.

\section{Gas exchange and leaf conductance measurements}

Leaf conductance $\left(g_{L}\right)$, transpiration rate $(E)$ and photosynthesis $(A)$ were obtained using a portable LI-COR 6400 gas exchange system (LI-COR Environmental, Lincoln, Nebraska, USA). All LI-COR measurements were obtained from three mature and fully expanded leaves from each plant per replicate, per treatment at the same time as infrared thermal images and $\psi_{s}$ measurements $(n=72)$. For the Variety trial, leaf conductance $\left(g_{L}\right)$ was measured on five mature and fully expanded leaves per plant and per variety ( $n=120)$ using a non-steady state porometer (AP4, Delta-T Devices, Cambridge, UK). All physiological measurements were performed immediately after thermal imaging acquisition and from the same plants at midday.

\section{Canopy size measurements}

Leaf area index (LAI) was obtained in February 2010 using a LAI-2000 plant canopy analyser (Licor Inc., Lincoln, Nebraska, USA). Canopy measurements 
were performed the day before of physiological and thermal image data acquisition using the same plants.

\section{Statistical analysis}

Principal component analysis (PCA) with full cross validation was used to obtained a hierarchy of variables analysed, to find patterns in the data, detection of outliers and to classify any combination of variables that could explain links between $I_{G}, C W S I$ and physiological and growth parameters measured. For PCA analysis, the Unscrambler ${ }^{\circledR}$ software (version $X 10.1$ CAMO, Oslo, Norway) was used. The dataset used for PCA analysis contained the following variables: $I_{G}, C W S I, \Psi_{s}$, and $L A I$.

Correlation analysis were used to compare: i) reference temperatures obtained using reference leaves from infrared thermal images (IRT leaves) and calculated using energy balance models (Eqs. 4 and 5), ii) CWSI and $I_{G}$ calculated from thermal images and physiological variables obtained from the same canopies. The correlation analysis was performed using the Curve Fitting Toolbox® (MATLAB® 2010b, Mathworks, Natick, MA, USA). Significance of correlations and separation of means between i) treatments, ii) infrared indices and iii) spatial distribution of indices within thermal images and were obtained using the CoStat statistical software (CoHort, Monterrey, CA, USA) and using the Student-Newman-Keuls test with a significance level of $P \leq 0.05$.

\section{RESULTS}


Outputs from the automated thermal image analysis

The semi-automated method was able to discriminate leaf material from sunny exposed leaves and non-leaf material using the threshold temperatures obtained from reference leaves. The example presented in Figure $2 \mathrm{a}$ shows a thermal image with considerable amount of branches, a few small gaps with very low temperature, located in the upper section of the canopy, corresponding to sky and a training system wire running horizontally in the upper half of the thermal image. Figure $2 b$ shows the filtered image in which it can be clearly seen the exclusion of non-leaf and sun-exposed material in dark blue by using the $T_{\text {wet }}$ and $T_{d r y}$ thresholds.

Reference temperatures and statistical analyses of automated outputs are presented in Tables 1 and 2 respectively. Table 1 shows the reference temperatures obtained for different treatments from the Chardonnay trial with non-significant differences between reference leaves. Table 2 shows the averaged outputs for thermal images obtained at midday (maximum atmospheric demand) at the Chardonnay trial. The data did not show significant differences for temperatures and indices shown in Table 2 from top, middle and bottom sections for each canopy. There were significant differences for temperatures and indices between treatments (Table 2). The control treatment showed the lowest $T_{c}\left(23.7^{\circ} \mathrm{C}\right), T_{\max }\left(24.2^{\circ} \mathrm{C}\right), T_{\min }(22.4$ ${ }^{\circ} \mathrm{C}$ ) and minimal difference between $T_{\max }$ and $T_{\min } . T_{\max }, T_{\min }$ and $T_{c}$ varied in the rest of the treatments with averaged $T_{\max }$ of $27.4{ }^{\circ} \mathrm{C}$ and $T_{\min }$ of $23.4{ }^{\circ} \mathrm{C}$ and $T_{c}$ of $25.9{ }^{\circ} \mathrm{C}$. The control treatment was significantly different from other treatments for all the parameters obtained and calculated from thermal images, with exception of $T_{\text {min. }}$. The $I_{G}$ and $C W S I$ values for the control 
treatment were in average 2.3 and 0.31 , respectively. The treatment with reduced water applied (10S) also differentiated statistically from the rest of the treatments for $T_{C}, I_{G}$ and $C W S /$ with averaged values of $26.4{ }^{\circ} \mathrm{C}, 0.24$ and 0.81 respectively. Moreover, the $I_{G}$ indices were not statistically different for the recovery treatments and $30 \mathrm{~S}$.

\section{Calculated versus reference leaves temperatures}

Figure 3 shows the relationship between the calculated $T_{\text {dry }}$ and $T_{\text {wet }}$ reference temperatures using Eqs. 4 and 5, compared to the reference leaves temperatures obtained using the analysis proposed and manual ROI analysis in MATLAB® (IRT leaves). There was a strong and significant correlation between IRT and calculated $T$ for two days of measurements (SEE = 10.16; $R^{2}=0.95 ;$ RMSE $\left.=0.85 ; p<0.001\right)$.

\section{Physiological and canopy growth response to water application}

Physiological responses of irrigation treatments and relationships between the variables measured $\left(\Psi_{s}\right.$ and $\left.L A\right)$ and indices calculated from thermal images $\left(C W S I\right.$ and $\left.I_{G}\right)$ are presented in Figure 4 as a PCA score plot (Fig. 4a) and a correlation loadings plot (Fig. 4b). The $I_{G}$ and $C W S I$ best differentiated and separated the control and $30 \mathrm{R}$ from other treatments, which are associated with values of $g_{L}$ of $278 \mathrm{mmol} \mathrm{m}^{-2} \mathrm{~s}^{-1}$ (control) and $178 \mathrm{mmol} \mathrm{m}^{-2} \mathrm{~s}^{-1}(30 \mathrm{R})$ in average, compared to $161 \mathrm{mmol} \mathrm{m}^{-2} \mathrm{~s}^{-1}(10 \mathrm{R})$ and $121 \mathrm{mmol} \mathrm{m}^{-2} \mathrm{~s}^{-1}$ (10S). Recovery treatments showed values of $\psi_{s}$ of $-0.45 \mathrm{MPa}$ on average. The $30 \mathrm{~S}$ and $10 \mathrm{~S}$ treatments reached values of $\psi_{s}=-0.61 \mathrm{MPa}$ and $-0.75 \mathrm{MPa}$, which can be considered as non water stressed and mild water stress conditions 
respectively for the experiment (Acevedo-Opazo et al., 2010). Canopy growth also responded to water applications. $L A /$ ranged from 3.87 corresponding to the $30 \mathrm{R}$ treatment to 2.15 corresponding to the $10 \mathrm{~S}$ treatment (Table 3 ). There were no significant differences between the control, 30R and 30S treatments, but they differentiated from the $10 \mathrm{~S}$ and 10R treatments. Canopy leaf area was reduced $35 \%$ for the $10 \mathrm{~S}$ and $10 \mathrm{R}$ treatments compared to control, $30 \mathrm{~S}$ and $30 \mathrm{R}$. The PCA in Figure $4 \mathrm{a}$ shows positive correlations between $I_{G}, \Psi_{s}$ and $L A I$. An inverse correlation was found for the previous variables and CWSI. The two factors shown in the PCA are factor 1 and factor 2 , which explained $81 \%$ and $17 \%$ of the variability in the data respectively. The two factors combined explained $98 \%$ of the data variability. Factor 1 was identified as vine water status and factor 2 as vegetative growth in response to water availability.

\section{Thermal imaging and physiological responses to irrigation}

Highly significant correlations were obtained between $g_{L}$ measured and $I_{G}$ and CWSI obtained using the semi-automated thermal image analysis method proposed in this paper for the Chardonnay and the variety trial (Table 4). Positive linear correlations were found, considering all treatments for the Chardonnay trial, between $g_{L}$ and $I_{G}$ at midday $\left(R^{2}=0.92\right.$; Fig. 5a) and for the Variety trial $\left(R^{2}=0.81 ;\right.$ Fig. $\left.6 a\right)$. Negative linear correlations were found between $g_{L}$ and $C W S I$ at midday for the Chardonnay trial $\left(\mathrm{R}^{2}=0.87\right.$; Fig. $\left.5 \mathrm{~b}\right)$ and the Variety trial $\left(R^{2}=0.83\right.$; Fig. $\left.6 b\right)$. These results are in agreement with studies by Grant et al. (2007), Leinonen et al. (2006) and Jones et al. (2002), which found that $I_{G}$ is proportional to $g_{L}$ for grapevines. Results for the 
relationship between $g_{L}$ and $C W S I$ also are in accordance to studies by Moller et al. (2007).

\section{Discrimination of wind influence in thermal images}

Mean values and statistical analysis obtained from the top, middle and bottom sections of the canopy submitted to wind are shown in Table 5. A statistically significant higher value of $I_{G}=3.30$ was found for the top section of the canopy. There were no statistically significant differences for the mean values of $I_{G}$ found for the middle $\left(I_{G}=1.16\right)$ compared to the bottom sections of the canopy $\left(I_{G}=1.09\right)$. Furthermore, a significantly higher standard deviation of means was found also for the top section of the canopy (SD = 2.97) compared to the middle and bottom sections ( $S D=0.54$ and 0.61 respectively).

Figure 7 shows the original thermal image submitted to windy conditions (Figure 7a). A more visible blue colour can be seen at the top part of the canopy (dashed square) compared to the bottom section, corresponding to higher $I_{G}$. Figure $7 \mathrm{~b}$ shows the filtered $I_{G}$ image in which all values above $I_{G}=$ 3.0 were forced to a light blue colour (top part) and all $I_{G}$ values below $I_{G}=0.3$ were forced to a red colour (bottom part). Higher and lower criteria were obtained from physiological data presented in Figure 5a.

\section{DICUSSION}

Reference leaves compared to leaf energy balance calculations

Results from comparisons between calculated $T_{\text {dry }}$ and $T_{\text {wet }}$ using ancillary information and those obtained using the reference leaves are in accordance 
to those obtained in previous studies (Leinonen et al., 2006b). Even though Leinonen et al. (2006b) found good correlations between IRT reference temperatures with calculated temperatures, the latter were more stable than those obtained using reference leaves. Furthermore, the calculated temperatures did not reflect the canopy-to-canopy variability of $T_{\text {dry }}$ and $T_{\text {wet }}$ as accurately as the painting method and reference leaves. This can be explained by the single estimation of reference temperatures from an automatic meteorological station located close to the vineyard site where the experiment was conducted. In our study, we obtained micrometeorological data from the Licor 6400 to compute calculated $T_{\text {dry }}$ and $T_{\text {wet, }}$ the result were higher correlations between reference temperatures from reference leaves (IRT) compared to calculated reference temperatures. Therefore, having microclimatic ancillary information helps to improve the estimation of $T_{d r y}$ and $T_{\text {wet }}$ making possible a higher degree of automation in the use of thermal images to obtain grapevine water status.

Further studies are required to acquire parallel microclimatic data using a customised mini-meteorological station along with the infrared thermal images to improve accuracy of $T_{\text {dry }}$ and $T_{\text {wet }}$ estimates. Specifically, to obtain the net isothermal radiation $\left(R_{n i}\right)$, which for the purpose of this study was assumed to be equal to the absorbed short-wave radiation. This assumption was based on studies made by Jones (1992) and Leinonen et al. (2006). Consecutive data acquisition and processing its possible using MATLAB® and the Instrument Control Toolbox® making the collection of infrared thermal images, ancillary weather information and calculations of $T_{d r y}, T_{\text {wet, }} I_{G}$ and $C W S I$ automatic. This 
integrated system will be tested in following seasons for grapevines and will be available as freeware to interested researchers in a beta version.

\section{Thermal indices and physiological measurements}

Results from the Chardonnay trial were consistent with previous physiological studies (season 2006-07) obtained from the same trial site for $\psi_{s}$ and $g_{L}$ (season 2009-10) (De Bei et al., 2011). Therefore, it can be said that physiological responses found for the period used for the Chardonnay trial were representative of the seasonal treatment response to irrigation. Our study on six varieties using a normalised stabilisation time of two minutes for the wet and dry leaves gave similar correlation values and significance compared to the Chardonnay trial. Variations observed in $g_{L}, I_{G}$ and $C W S I$ can be attributed to: i) differences in stomatal response due to differences in phenological stage and water requirements of the different varieties and ii) spatial variability within the irrigation block (water application), which was assessed through a drip uniformity test ( $d u=81 \%$, data not shown).

The PCA in Figure 4a, separated the irrigation treatments explaining a higher percentage of variability ( $81 \%)$ due to plant water status (Factor 1$)$. Statistical analysis showed that the $10 \mathrm{~S}, 10 \mathrm{R}$ and $30 \mathrm{~S}$ were the treatments that presented mild water stress (higher CWSI and lower $\psi_{s}$ and $g_{L}$ and $I_{G}$ ) compared to control and $30 \mathrm{R}$ for the days of the experiment. There was higher variability for data from the control and 30R treatments compared to $30 \mathrm{~S}, 10 \mathrm{R}$ and $10 \mathrm{~S}$ along the $I_{G}$ vector, which has been shown to be proportional to $g_{L}$ (Leinonen et al., 2006a; Leinonen and Jones, 2004b). This effect on water stress treatments can be explained by higher stomatal 
regulation due to reductions in water supplied to the vines. It has been shown that chemical signals from root-to-shoot, mainly abscisic acid (ABA), increases stomatal sensitivity to VPD due to soil moisture depletion and roots exposed to drying soil (Collins et al., 2009; Fuentes et al., 2005b). A strong and significant inverse correlation between $\Psi_{s}$ and CWSI found in this study $\left(R^{2}=0.75 ;\right.$ SSE $=0.034 ;$ RMSE $\left.=0.11\right)$ is in accordance to studies made by Moller et al. (2007). Factor 2 on the PCA was related to vigour, which was affected by long-term levels of water supply by irrigation (Figs. 4a and 4b).

\section{Leaf area index}

Canopy growth and architecture can affect the amount of sun-exposed leaf material and therefore, the amount of filtering required per thermal image. Control treatments, with a higher $L A I$, will present more shading and bigger canopy walls. On the contrary, water stress treatments will present significantly smaller canopies with a higher gap fraction, which will result in more sun-exposed leaf material.

Canopy growth, measured as $L A I$, did not affect significantly thermal properties of reference leaves. Even though there were non-significant differences among reference leaves, the control treatment registered the lowest averaged temperature compared to the rest of the treatments (Table 1). Factors such as: canopy growth, structure, leaf area and thickness and their influence in thermal properties of reference leaves and canopy temperature need to be studied in more detail for different varieties under water stress treatments. 
Automated differential analysis of $I_{G}$ within the canopy

The separation of thermal image analysis between top, middle and bottom regions allowed the detection of wind velocity influence on the spatial variability of canopy thermal signature, which according to the training system used in the Chardonnay trial (Scott Henry) is expected to be more influential in the top sections of canopies for transversal winds in relation to row orientation. According to Jones et al. (2002), canopy temperatures, and hence reference temperatures and calculated indices, start to change considerably at wind velocities $(u)$ of around $1 \mathrm{~m} \mathrm{~s}^{-1}$. This effect is mainly due to the removal of the boundary layer resistance to water vapour from the surface of leaves, which increases leaf transpiration, and therefore $I_{G}$, in non water stress conditions. In our study, infrared thermal images were always obtained in very calm wind conditions to minimise this effect for validation purposes of the infrared technique.

The spatial analysis tools proposed in this study can be used as a data quality assessment for data obtained from sites with moderate wind conditions. In the example presented in this paper (Table 5 and Figure 7), mild wind conditions were forced upon the top part of the canopies of well-irrigated Chardonnay vines. The customised sub-division tool and analysis allowed detecting the changes of canopy temperature in the top section by statistically analysing changes on the calculated $I_{G}$ index spatially within the canopies. In regards to the analysis time, it did not vary considerably when changing the $d$ value from 10 to 250 , the latter corresponding to the sub-division of an image to the maximum possible value, or pixel-by-pixel (approx. 3 to 6 seconds per image using a Mac Book Pro®, 8Gb RAM, 2.7 GHz, core i7). However, this small 
difference in analysis time could become important when batch-analysing several images.

Since the automatic division (top, middle and bottom) and the customised sub-division tools filter each sub-image using $T_{d r y}$ and $T_{\text {wet, }}$, non-leaf material is generally excluded from the differential analysis. Therefore, gaps that show sky, which are below zero due to lack of reflection, will not be included as possible wind effect. Furthermore, leaves that are too damaged by senescence, insect or disease attacks will loose their capacity of thermal regulation through transpiration (presenting temperatures closer or higher than $T_{d r y}$ ), which could fall into the non-leaf material thermal range. This effect can be seen in Figure 7, where the dry and wet reference leaves (bottom right) were left with petroleum jelly and the water solution for more than 10 mins after application. After this time, $T_{\text {wet }}$ increased temperature and was not included as "anomalous" low temperature in the analysis, since the specific $I_{G}$ value for this leaf was $I_{G}=2.0$. Three leaves were included in the criteria of $I_{G}$ $\leq 0.3$ (from Fig. 5a), which were located in the bottom part of the image. These leaves corresponded to the $T_{d r y}$ and two leaves that showed signs of senescence assessed visually (red and yellow colours).

Further development of the code has been started to incorporate direct statistical analysis tools to assess spatial differences within canopies that can explain variability of data from single infrared thermal images.

\section{Use of thermal indices for irrigation scheduling}

For a potential application of infrared thermography in irrigation scheduling, it would be recommended to use the $I_{G}$ data obtained in the period of maximum 
atmospheric demand to assess plant water status (Flexas et al., 2002). This is the same time of the day and conditions that has been commonly used to measure midday $\psi_{s}$, which is considered one of the most integrative plant water status parameters since it integrates the soil-plant-atmosphere conditions at the time of measurement (Acevedo-Opazo et al., 2010; Chone et al., 2001). Other researches have shown correlations between $I_{G}$ and $\Psi_{s}$ using manual thermal image analysis techniques (Moller et al., 2007) and lower correlations using other automated methods (Wang et al., 2010).

Furthermore, a more automated procedure of acquiring thermal images and relevant data for analysis can be achieved by using microclimatic ancillary information obtained at the same time and locations of thermal imaging data. The extra cost of implementing this method will not be significant due to the low price of reliable sensors that can be integrated in thermal camera system. Further research has been started by our group to automatically integrate infrared imagery collection from the field, ancillary microclimatic data and data processing using the method proposed in this paper to obtain real time plant water status assessment. The latter method will allow obtaining and analysing a higher volume of data for a more representative spatial and temporal assessment of grapevine water status within the canopy and field scales.

\section{CONCLUSIONS}

This paper has proposed the use of a semi-automated and automated infrared image analysis technique to obtain accurate plant water status indicators using MATLAB® programming tools. Results can be acquired in a rapid form to be statistically analysed and be applied for experimental research or 
potentially irrigation scheduling management and decision-making. Further studies will be conducted to automate the data acquisition and analysis for real time assessment. Since this methodology considers the automated separation of top, middle and bottom sections of the canopy, plus a customised sub-division of thermal image for variability analysis within a canopy, data quality techniques can be implemented to assess the influence of wind speed on the variability of estimation of $I_{G}$ and $C W S I$ or potentially the detection of biotic and abiotic stresses from sections of the canopy. These tools can be of great help for other experimental trials that are more specific in the study of these stresses. The use of these automated tools could allow the implementation of precision irrigation scheduling according to the specific physiological behaviour of different grapevine varieties and their responses to water application. Due to the sensitivity of infrared thermography, this technique can be used to implement irrigation techniques such as regulated deficit irrigation $(\mathrm{RDI})$ or partial root-zone drying (PRD), which require narrow plant water status thresholds to maximise quality of grapes, water use efficiency and minimise detrimental effects on yield.

\section{AKNOWLEDGEMENTS}

This project is supported by Australia's grape growers and winemakers through their investment body the Grape and Wine Research and Development Corporation, with matching funds from the Australian Government. The four organisations, involved in this research project, UoA, 
CSIRO, SARDI, AWRI, are all part of the Wine Innovation Cluster (www.wineinnovationcluster.com). This project is being undertaken on a collaborative basis by the parties. The authors thank staff from Yalumba Nurseries whose in-kind contributions have included irrigation supplies, irrigation system conversion and management of the vineyard, staff from the Irrigated Crop Management Service (ICMS) who designed the irrigation system conversion and have provided ongoing irrigation system advice, staff at Measurement Engineering Australia (MEA) for in-kind contribution of field monitoring equipment. 
TABLES

Table 1: Infrared reference temperatures ( $T_{\text {dry }}$ and $T_{\text {wet }}$ ) and canopy temperatures $\left(T_{c}\right)$ obtained from reference thermal images. Standard deviations $(S D)$ correspond to the ROI selected for the Chardonnay trial. All values are in ${ }^{\circ} \mathrm{C}$.

\begin{tabular}{|c|c|c|c|c|c|c|}
\hline Treatment & $\mathrm{T}_{\text {dry }}$ & $\mathrm{SD} \mathrm{T}_{\mathrm{d} y}$ & $\mathrm{~T}_{\text {wet }}$ & $\mathrm{SD} \mathrm{T}_{\text {wet }}$ & $\mathrm{T}_{\mathrm{c}}$ & $\mathrm{SD} \mathrm{T}_{\mathrm{c}}$ \\
\hline 10R; 10S & 27.1 & 0.42 & 22.8 & 0.94 & 25.2 & 0.48 \\
\hline 30R; 30S & 27.7 & 0.72 & 22.4 & 1.29 & 25.9 & 0.64 \\
\hline Control & 27.0 & 0.34 & 22.2 & 0.67 & 23.6 & 0.54 \\
\hline
\end{tabular}


Table 2: Averaged values of temperatures in ${ }^{\circ} \mathrm{C}$ for canopy $\left(T_{c}\right)$, maximum canopy temperature $\left(T_{\max }\right)$, minimum canopy temperature $\left(T_{\min }\right), I_{G}$ and $C W S I$ from infrared thermal images. Chardonnay trial.

\begin{tabular}{|c|c|c|c|c|c|c|}
\hline Position & Treatment & $T_{c}$ & $T_{\max }$ & $T_{\min }$ & $I_{G}$ & CWSI \\
\hline \multirow[t]{5}{*}{$T_{o p}^{\text {ns }}$} & $10 \mathrm{R}$ & $26.6^{\text {ab }}$ & $27.2^{b}$ & $23.5^{\mathrm{ab}}$ & $0.57^{\mathrm{bc}}$ & $0.65^{b}$ \\
\hline & $10 S$ & $26.4^{a}$ & $27.2^{b}$ & $23.9^{a}$ & $0.22^{\mathrm{c}}$ & $0.82^{a}$ \\
\hline & $30 \mathrm{R}$ & $25.2^{b}$ & $27.5^{a}$ & $22.9^{\text {ab }}$ & $0.95^{b}$ & $0.52^{b}$ \\
\hline & $30 S$ & $25.6^{\mathrm{ab}}$ & $27.7^{\mathrm{a}}$ & $23.1^{\mathrm{ab}}$ & $0.65^{\mathrm{bc}}$ & $0.61^{b}$ \\
\hline & Control & $23.7^{c}$ & $24.2^{c}$ & $22.5^{\mathrm{b}}$ & $2.22^{a}$ & $0.32^{c}$ \\
\hline \multirow[t]{5}{*}{ Middle $^{\text {ns }}$} & $10 \mathrm{R}$ & $25.7^{b}$ & $27.2^{b}$ & $23.5^{\mathrm{ab}}$ & $0.51^{\mathrm{bc}}$ & $0.67^{b}$ \\
\hline & $10 \mathrm{~S}$ & $26.4^{\mathrm{a}}$ & $27.2^{b}$ & $24.1^{\mathrm{a}}$ & $0.23^{c}$ & $0.82^{a}$ \\
\hline & $30 \mathrm{R}$ & $25.1^{\mathrm{c}}$ & $27.6^{a}$ & $22.9^{b}$ & $1.01^{b}$ & $0.51^{\mathrm{c}}$ \\
\hline & $30 S$ & $25.7^{b}$ & $27.7^{a}$ & $23.1^{\text {ab }}$ & $0.63^{\mathrm{bc}}$ & $0.62^{b}$ \\
\hline & Control & $23.7^{d}$ & $24.2^{\mathrm{c}}$ & $22.4^{\mathrm{b}}$ & $2.21^{a}$ & $0.32^{d}$ \\
\hline \multirow[t]{5}{*}{ Bottom $^{\text {ns }}$} & $10 \mathrm{R}$ & $25.5^{b}$ & $27.2^{b}$ & $23.1^{\text {ns }}$ & $0.67^{\mathrm{bc}}$ & $0.62^{b}$ \\
\hline & $10 \mathrm{~S}$ & $26.3^{a}$ & $27.2^{b}$ & $23.7^{\mathrm{ns}}$ & $0.27^{c}$ & $0.80^{\mathrm{a}}$ \\
\hline & $30 \mathrm{R}$ & $25.0^{b}$ & $27.6^{\mathrm{ab}}$ & $23.3^{\text {ns }}$ & $1.12^{b}$ & $0.49^{c}$ \\
\hline & $30 S$ & $25.6^{b}$ & $27.7^{a}$ & $23.4^{\text {ns }}$ & $0.66^{\mathrm{bc}}$ & $0.61^{\mathrm{bc}}$ \\
\hline & Control & $23.6^{c}$ & $24.2^{\mathrm{C}}$ & $22.2^{\text {ns }}$ & $2.46^{\mathrm{a}}$ & $0.30^{d}$ \\
\hline
\end{tabular}

Means followed by different letters are different at $\mathrm{P} \leq 0.05$ and ns correspond to non-significant differences. 
Table 3: Canopy size results ( $L A I)$ measured in February 2011 per irrigation treatments. Chardonnay trial.

\begin{tabular}{|c|c|}
\hline Treatment & LAI \\
\hline $10 \mathrm{R}$ & $2.54^{\mathrm{b}}$ \\
\hline $10 \mathrm{~S}$ & $2.15^{\mathrm{b}}$ \\
\hline $30 \mathrm{R}$ & $3.87^{\mathrm{a}}$ \\
\hline $30 \mathrm{~S}$ & $3.37^{\mathrm{a}}$ \\
\hline Control & $3.62^{\mathrm{a}}$ \\
\hline
\end{tabular}

Means followed by different letters are different at $\mathrm{P} \leq 0.05$ and ns correspond to non-significant differences. 
Table 4: Results of correlations between leaf conductance $\left(g_{L}\right)$, the infrared index $\left(I_{G}\right)$, crop water stress indices (CWSI) calculated by infrared thermal image analysis for the Chardonnay and the Variety trials.

\begin{tabular}{|c|c|c|c|c|c|}
\hline Trial & Dataset & $\mathrm{R}^{2}$ & SEE & RMSE & Significance \\
\hline Chardonnay & $g_{L}$ vs $I_{G}$ & 0.92 & 0.56 & 0.18 & $\mathrm{P}<0.001$ \\
\cline { 2 - 6 } & $g_{L}$ vS CWSI & 0.86 & 0.03 & 0.04 & $\mathrm{P}<0.001$ \\
\hline Varieties & $g_{L}$ VS $I_{G}$ & 0.87 & 0.14 & 0.12 & $\mathrm{P}<0.001$ \\
\cline { 2 - 6 } & $g_{L}$ vS CWSI & 0.83 & 0.04 & 0.06 & $\mathrm{P}<0.001$ \\
\hline
\end{tabular}


Table 5: Results of the sub-division tool on a thermal image from a canopy submitted to wind velocities of $1.39 \mathrm{~m} \mathrm{~s}^{-1}$ on the top section. $I_{G}$ values correspond to the mean from a particular section of the infrared thermal image.

\begin{tabular}{|c|c|c|c|c|}
\hline Trial & Section & $I_{G}$ & SD & Significance \\
\hline Chardonnay & Top & $3.30^{\mathrm{a}}$ & 2.97 & \multirow{2}{*}{$\mathrm{P}<0.001$} \\
\cline { 2 - 4 } & Middle & $1.16^{\mathrm{b}}$ & 0.54 & \\
\cline { 2 - 4 } & Bottom & $1.09^{\mathrm{b}}$ & 0.61 & \\
& & & \multicolumn{2}{|}{} \\
\hline
\end{tabular}

Means followed by different letters are different at $\mathrm{P} \leq 0.05$ and ns correspond to non-significant differences. $\mathrm{SD}=$ standard deviation of the mean. 


\section{FIGURES}

Figure 1: (a) Example of digital image from a grapevine canopy depicting the dry and wet reference leaves with a red and blue arrow respectively, (b) corresponding infrared thermal image, (c) temperature frequency distributions considering the whole thermal image and (d) considering only the range between $T_{\text {dry }}$ and $T_{\text {wet }}(\mathrm{d})$. Dry and wet reference leaves can be seen in the bottom left corner of Fig. 1b. From Fuentes et al. (2005).

Figure 2: (a) Example of infrared thermal images obtained using reference leaves (middle right) and (b) filtered thermal image using $T_{\text {wet }}$ and $T_{\text {dry }}$ as thresholds. Dark blue colour in the filtered image corresponds to non-leaf or exposed leaf material exclusion. Colourbar shows temperatures in ${ }^{\circ} \mathrm{C}$ for the Chardonnay trial.

Figure 3: Comparison between temperature thresholds obtained from reference leaves (IRT $\mathrm{T}$ in ${ }^{\circ} \mathrm{C}$ ) and calculated using energy balance algorithms (Eqs. 4 and 5). $T_{d r y}$ (filled circles) and $T_{\text {wet }}$ (clear circles) corresponded to two days of measurements $\left(18^{\text {th }}\right.$ and $19^{\text {th }}$ of February 2011).

Figure 4: (a) Principal component analysis (PCA) showing the separation of treatments for the Chardonnay trial by the score plot and (b) the correlation loadings showing the relationship between the physiological variables measured: leaf conductance $\left(g_{L}\right)$ and stem water potential $\left(\Psi_{s}\right)$, the thermal indices calculated: infrared index $\left(I_{G}\right)$, crop water stress indices (CWSI) and canopy growth $(L A)$. 
Figure 5: (a) Relationship between leaf conductance $\left(g_{L}\right)$ and infrared index calculated for thermal images and (b) with crop water stress index (CWSI) for the Chardonnay trial.

Figure 6: (a) Relationship between leaf conductance $\left(g_{L}\right)$ and infrared index calculated for thermal images and (b) with crop water stress index (CWSI) for the Variety trial. Each point corresponds to the averaged values of four plants per variety measured in two days, six days apart.

Figure 7: (a) Thermal image from a control canopy submitted to wind at the top section. Dashed rectangle shows roughly the area where wind was applied. Dashed circles indicate gaps in the canopy with low temperatures. User-defined polygons at the bottom right are the wet and dry reference leaves. (b) Filtered $I_{G}$ image obtained using the customised sub-division tool with a $\mathrm{d}=12$ corresponding to 144 sub-divisions. Values of $I_{G} \geq 3$ were coloured light blue and $I_{G} \leq 0.3$ were coloured red to denote areas influenced by wind or consistent temperatures close to the $T_{d r y}$ threshold respectively.

\section{REFERENCES}

Acevedo-Opazo, C., Ortega-Farias, S. and Fuentes, S., 2010. Effects of grapevine (Vitis vinifera L.) water status on water consumption, vegetative growth and grape quality: An irrigation scheduling application to achieve regulated deficit irrigation. Agricultural Water Management, 97(7): 956-964. 
Chone, X., Van Leeuwen, C., Dubourdieu, D. and Gaudillere, J.-P., 2001. Stem water potential is a sensitive indicator of grapevine water status. Annals of Botany, 87: 477-483.

Cifre, J., Bota, J., Escalona, J.M., Medrano, H. and Flexas, J., 2005. Physiological tools for irrigation scheduling in grapevine (Vitis vinifera L.): an open gate to improve water-use efficiency? Agriculture, Ecosystems \& Environment, 106(2/3): 159-170.

Collins, M.J., Fuentes, S. and Barlow, E.W.R., 2009. Partial rootzone drying and deficit irrigation increase stomatal sensitivity to vapour pressure deficit in anisohydric grapevines. Functional Plant Biology, in press.

De Bei, R., Cozzolino, D., Sullivan, W., Cynkar, W., Fuentes, S., Dambergs, R., Pech, J. and Tyerman, S., 2011. Non-destructive measurement of grapevine water potential using near infrared spectroscopy. Australian Journal of Grape and Wine Research, 17(1): 62-71.

Ferrini, F., Mattii, G.B. and Nicese, F.P., 1995. Effect of Temperature on Key Physiological Responses of Grapevine Leaf. Am. J. Enol. Vitic., 46(3): 375-379.

Flexas, J., Bota, J., Escalona, J., eacute, M., Sampol, B., Medrano, H., oacute and lito, 2002. Effects of drought on photosynthesis in grapevines under field conditions: an evaluation of stomatal and mesophyll limitations. Functional Plant Biology, 29(4): 461-471.

Fuentes, S., Collins, M., Rogers, G., Kelley, G. and Conroy, J., 2005a. Use of infrared thermography to assess spatial and temporal variability of stomatal conductance of grapevines under partial rootzone drying: An irrigation scheduling application. Acta Horticulturae, 689: 309-316.

Fuentes, S., Conroy, J.P., Rogers, G., Kelley, G. and Collins, M., 2005b. Use of infrared themography to assess spatial and temporal variability of stomatal conductance of grapevines under partial rootzone drying. An irrigation scheduling application. Acta Horticulturae, 689: 309-316.

Fuentes, S., Palmer, A.R., Taylor, D., Zeppel, M., Whitley, R. and Eamus, D., 2008. An automated procedure for estimating the leaf area index (LAI) of woodland ecosystems using digital imagery, MATLAB programming and its application to an examination of the relationship between 
remotely sensed and field measurements of LAI. Functional Plant Biology, 35(10): 1070-1079.

Grant, O.M., Tronina, Å., Jones, H.G. and Chaves, M.M., 2007a. Exploring thermal imaging variables for the detection of stress responses in grapevine under different irrigation regimes. Journal of Experimental Botany, 58(4): 815-825.

Grant, O.M., Tronina, L., Jones, H.G. and Chaves, M.M., 2007b. Exploring thermal imaging variables for the detection of stress responses in grapevine under different irrigation regimes. Journal of Experimental Botany, 58(4): 815-825.

Guilioni, L., Jones, H.G., Leinonen, I. and Lhomme, J.P., 2008. On the relationships between stomatal resistance and leaf temperatures in thermography. Agricultural and Forest Meteorology, 148(11): 19081912.

Idso, S.B., 1982. Non-water-stressed baselines: A key to measuring and interpreting plant water stress. Agricultural Meteorology, 27(1-2): 59-70. Jones, H.G., 1992. Plants and microclimate: a quantitative approach to environmental plant physiology. Cambridge University Press, 413 pp.

Jones, H.G., 1999a. Use of infraerd thermometry for estimation of stomatal conductance as a possible aid to irrigation scheduling. Agricultural and Forest Meterology, 95: 139-149.

Jones, H.G., 1999b. Use of thermography for quantitative studies of spatial and temporal variation of stomatalconductance over leaf surfaces. Plant, Cell and Environment, 22: 1043-1055.

Jones, H.G., 2004. Irrigation scheduling: advantages and pitfalls of plantbased methods. Journal of Experimental Botany, 55(407): 2427-2436.

Jones, H.G., Stoll, M., Santos, T., de Sousa, C., Chaves, M.M. and Grant, O.M., 2002a. Use of infrared thermography for monitoring stomatal closure in the field: application to grapevine. Journal of Experimental Botany, 53(378): 2249-2260.

Jones, H.G., Stoll, M., Santos, T., de Sousa, C., Chaves, M.M. and Grant, O.M., 2002b. Useof infra-red thermography formonitoring stomatalclosure in the field: application to the grapevine. Journal of Experimental Botany, 53: 2249-2260. 
Jones, H.G. and Vaughan, R.A., 2010. Remote sensing of vegetation. Principles, practices and applications. Oxford University Press, New York, $353 \mathrm{pp}$.

Leinonen, I., Grant, O.M., Tagliavia, C.P.P., Chaves, M.M. and Jones, H.G., 2006a. Estimating stomatal conductance with thermal imagery. Plant Cell and Environment, 29(8): 1508-1518.

Leinonen, I., Grant, O.M., Tagliavia, C.P.P., Chaves, M.M. and Jones, H.G., 2006b. Estimating stomatal conductance with thermal imagery. Plant, Cell \& Environment, 29(8): 1508-1518.

Leinonen, I. and Jones, H.G., 2004a. Combining thermal and visible imagery for estimating canopy temperature and identifying plant stress. Journal of Experimental Botany, 55(401): 1423-1431.

Leinonen, I. and Jones, H.G., 2004b. Combining thermal and visible imagery for estimating canopy temperature and identifying plant stress. Journal of Experimental Botany, 55(401).

Lindenthal, M., Steiner, U., Dehne, H.-W. and Oerke, E.-C., 2005. Effect of Downy Mildew Development on Transpiration of Cucumber Leaves Visualized by Digital Infrared Thermography. Phytopathology, 95(3): 233-240.

Lu, P., Yunusa, I.A.M., Walker, R.R. and Iler, W.J., 2003. Regulation of canopy conductance and transpiration and their modelling in irrigated grapevines. Functional Plant Biology, 30(6): 689-698.

Moller, M., Alchanatis, V., Cohen, Y., Meron, M., Tsipris, J., Naor, A., Ostrovsky, V., Sprintsin, M. and Cohen, S., 2007. Use of thermal and visible imagery for estimating crop water status of irrigated grapevine. Journal of Experimental Botany, 58(4): 827-838.

Stoll, M., Schultz, H., Baecker, G. and Berkelmann-Loehnertz, B., $2008 \mathrm{a}$. Early pathogen detection under different water status and the assessment of spray application in vineyards through the use of thermal imagery. Precision Agriculture, 9(6): 407-417.

Stoll, M., Schultz, H.R. and Berkelmann-Loehnertz, B., 2008b. Exploring the sensitivity of thermal imaging for Plasmopara viticola pathogen detection in grapevines under different water status. Functional Plant Biology, 35(4): 281-288. 
Stoll, m., Schultz, H.R. and Berkelmann-Loehnertz, B., 2008c. Thermal sensitivity of grapevine leaves affected by Plasmopora viticola and water stress. Vitis, 2: 133-134.

Tanner, C.B., 1963. Plant temperatures. Agronomy Journal, 55: 210-211.

Wang, X., Yang, W., Wheaton, A., Cooley, N. and Moran, B., 2010. Automated canopy temperature estimation via infrared thermography: A first step towards automated plant water stress monitoring. Comput. Electron. Agric., 73(1): 74-83. 

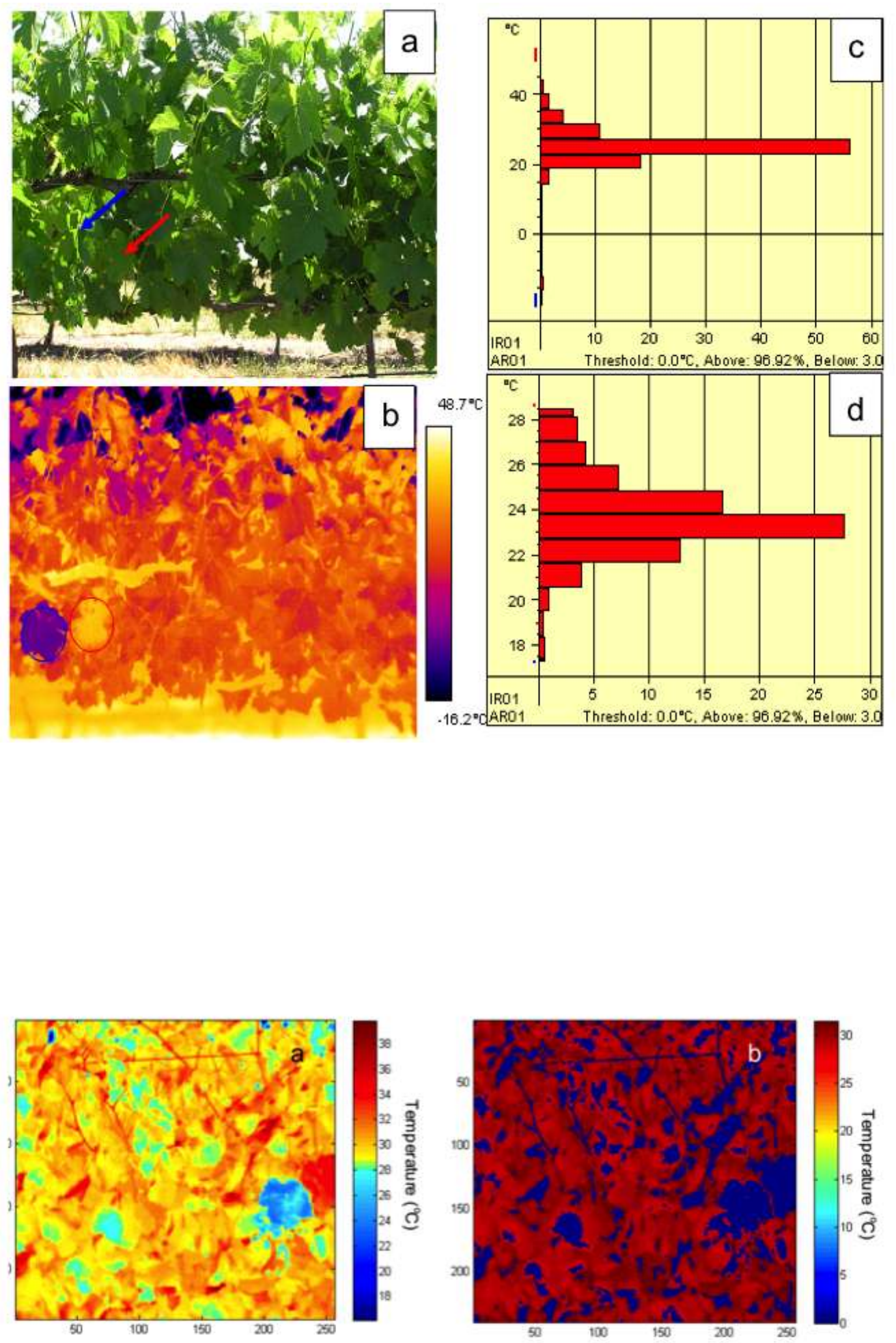

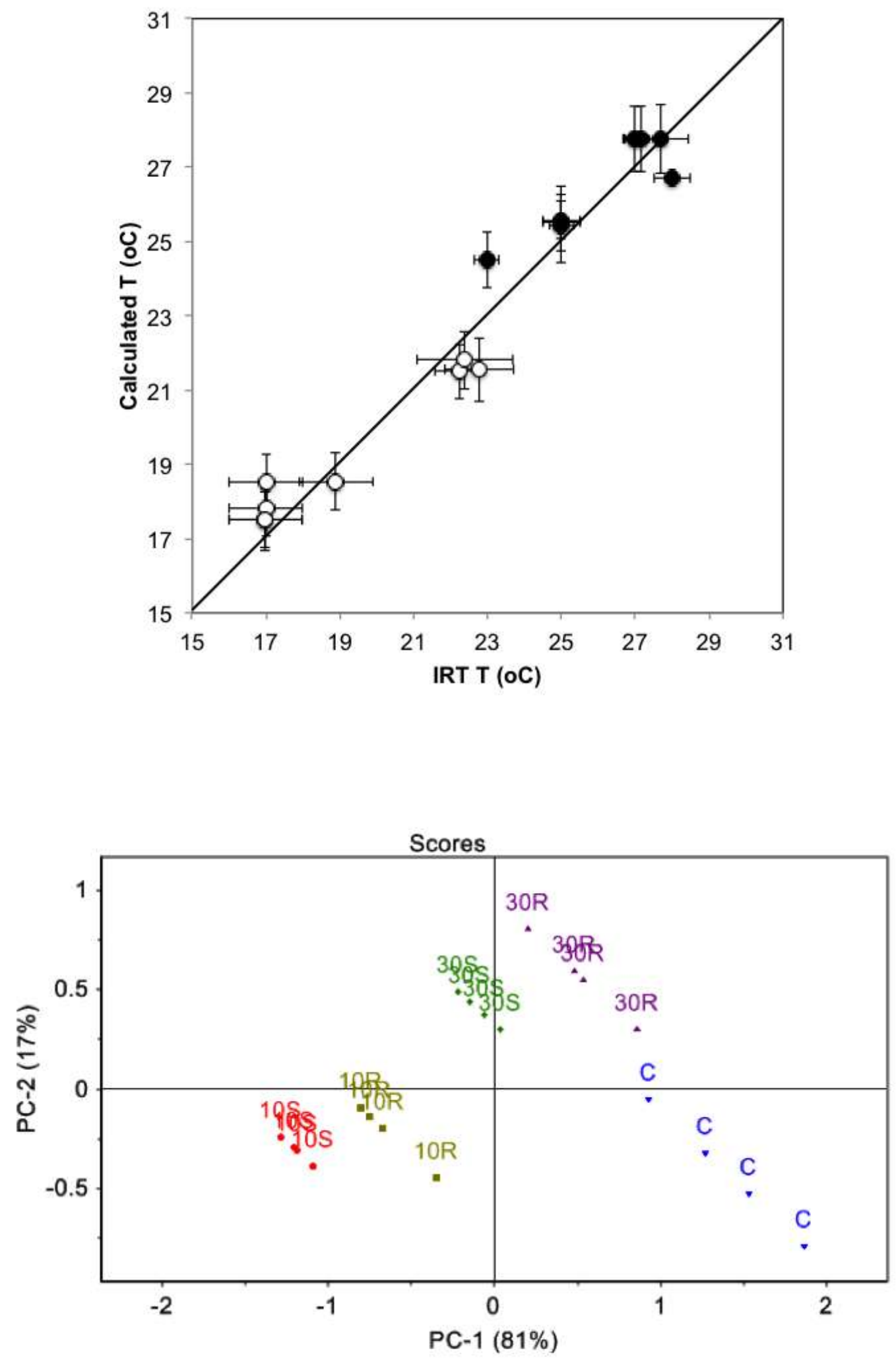

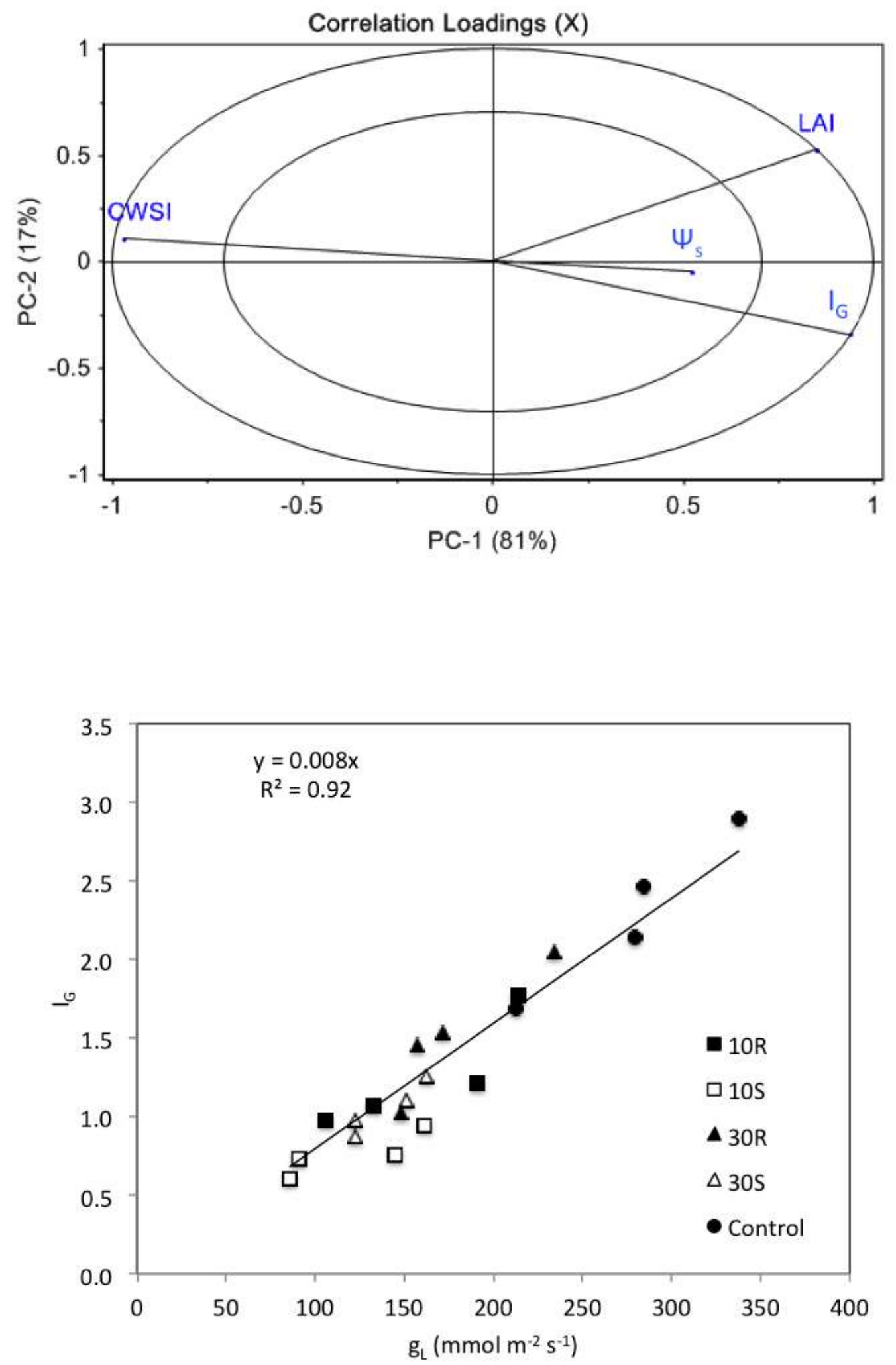

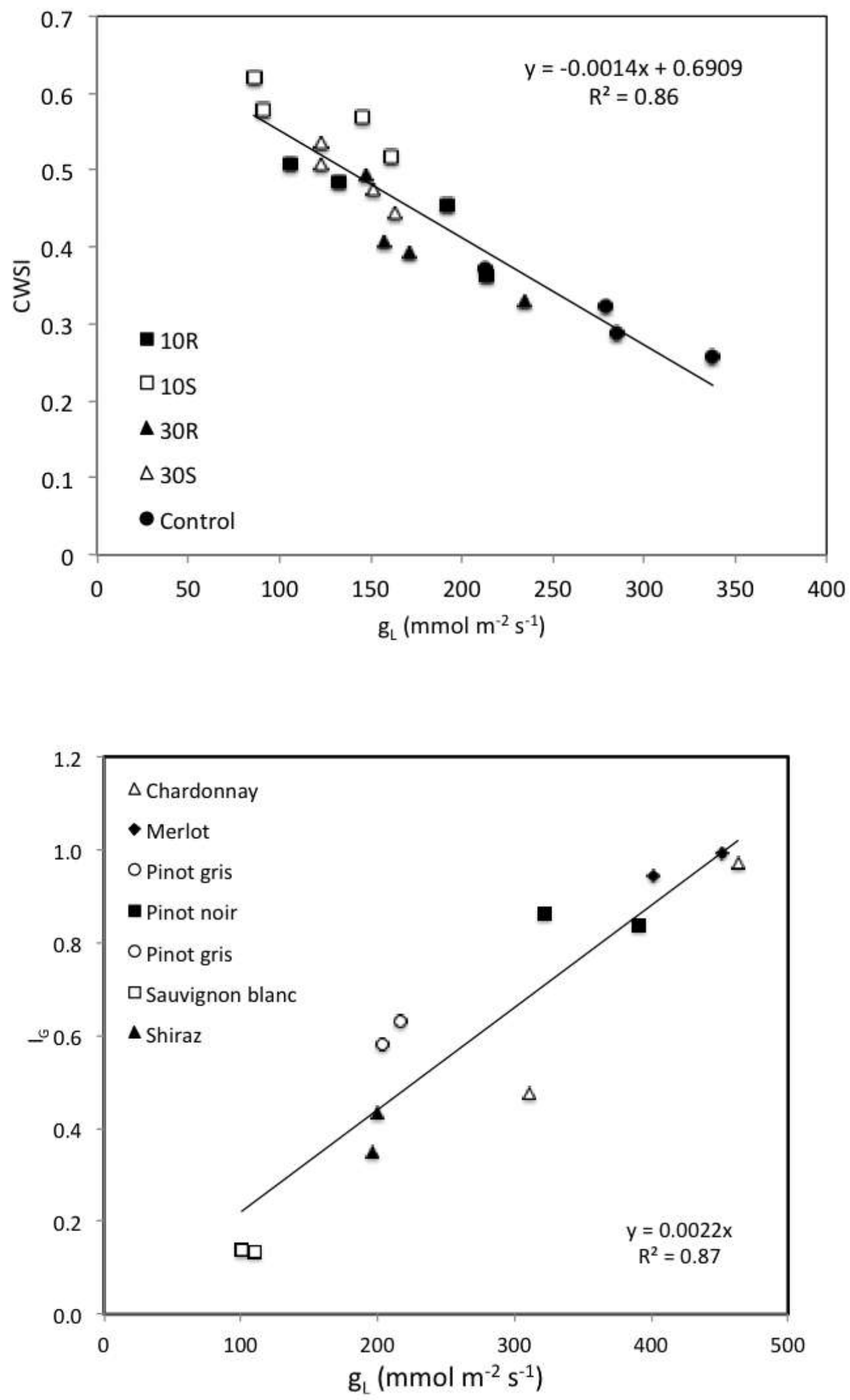

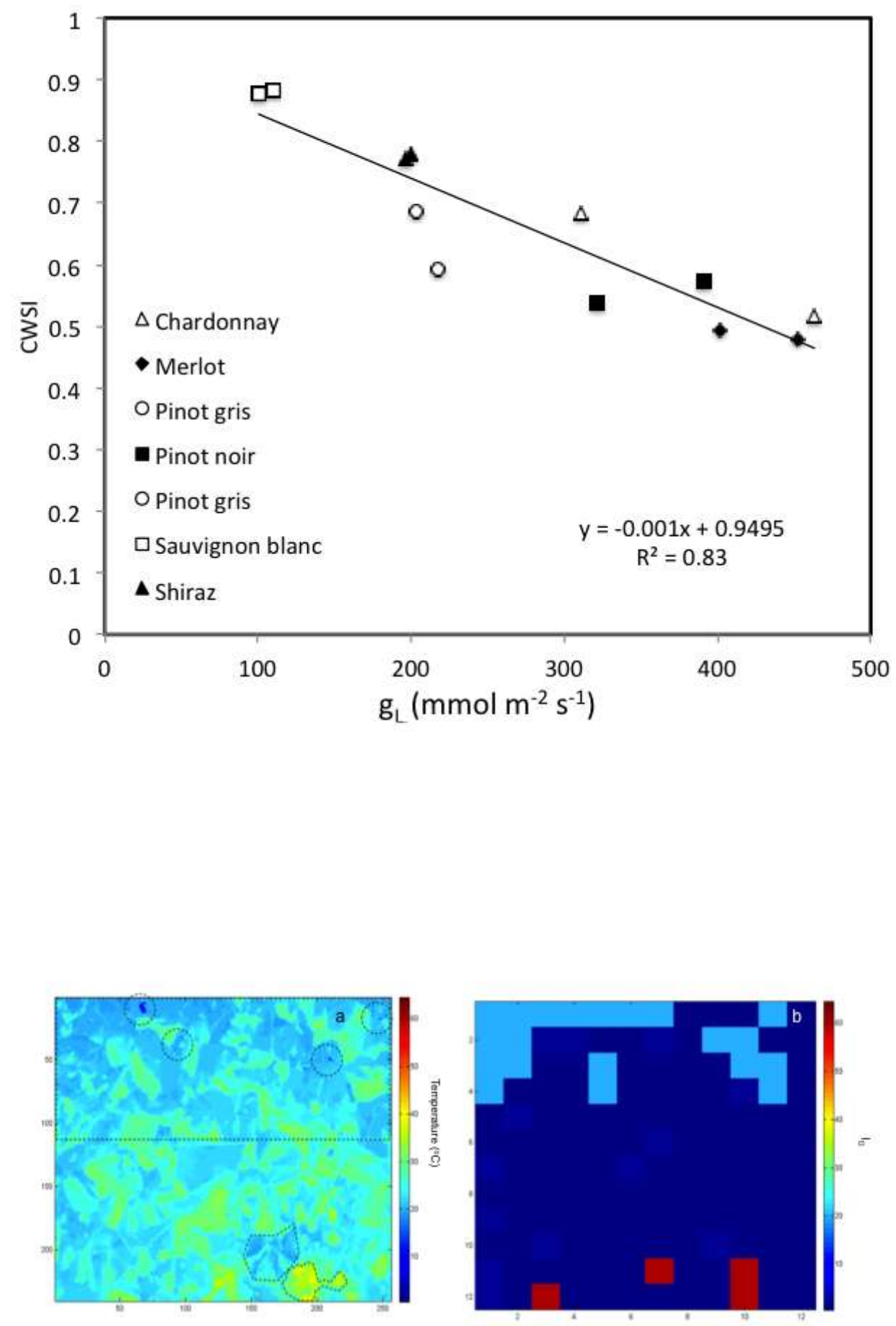


\section{University Library}

\section{- M M N E R VA A gateway to Melbourne's research publications}

Minerva Access is the Institutional Repository of The University of Melbourne

Author/s:

Fuentes, S;De Bei, R;Pech, J;Tyerman, S

Title:

Computational water stress indices obtained from thermal image analysis of grapevine canopies

Date:

2012-11-01

Citation:

Fuentes, S., De Bei, R., Pech, J. \& Tyerman, S. (2012). Computational water stress indices obtained from thermal image analysis of grapevine canopies. IRRIGATION SCIENCE, 30 (6), pp.523-536. https://doi.org/10.1007/s00271-012-0375-8.

Persistent Link:

http://hdl.handle.net/11343/283200 